Original Research

\title{
Drought Analysis Using Satellite-Based Data and Spectral Index in Upper Northeastern Thailand
}

\author{
Yannawut Uttaruk ${ }^{1}$, Teerawong Laosuwan ${ }^{2 *}$ \\ ${ }^{1}$ Department of Biology, Faculty of Science, Mahasarakham University, Maha Sarakham, Thailand \\ ${ }^{2}$ Department of Physics, Faculty of Science, Mahasarakham University, Maha Sarakham, Thailand
}

Received: 6 July 2018

Accepted: 8 September 2018

\begin{abstract}
Drought is one of the major natural disasters in Thailand, causing significant damage as it greatly affects farming, mostly in the northeastern region of Thailand. The objective of this study was to present a drought analysis using data from the Terra Modis satellite and spectral index in the upper northeastern study area, approximately $52,504.65 \mathrm{~km}^{2}$. In operation the Standardized Vegetation Index (SVI) was analyzed, based on calculations from the normalized differences vegetation index (NDVI) values Terra Modis satellite to examine the distribution of plants during 2014-2016. The study found that the largest drought area was in the year 2014, representing $93.12 \%$ (or $48,892.33 \mathrm{~km}^{2}$ ), followed by the year 2015 representing $87.02 \%$ (or $45,689.54 \mathrm{~km}^{2}$ ), and the year 2016 representing $86.42 \%$ (or $45,374.51 \mathrm{~km}^{2}$ ), respectively. The three-year SVI analysis results showed that the statistical correlation of rainfall during the same period is high. The results of this study indicated that drought analysis based on data from Terra Modis effectively identified the patterns of drought-prone areas.
\end{abstract}

Keywords: drought; remote sensing; terra modis; NDVI; SVI

\section{Introduction}

Drought is a natural disaster that occurs in many parts of Thailand and is a serious problem and an obstacle to national development. Areas with drought conditions often have water shortages for their consumption, including water for agriculture. While Thai agriculture is based on natural rainwater, if there is insufficient water, crop yields will be reduced, resulting in shortages of agricultural products and processed products for both domestic consumption and export.

*e-mail: teerawong@msu.ac.th
Drought has a direct impact on the economy and has indirect impacts on society and culture, as people abandon their habitat and migrate to work in cities when farming is not possible. In addition, very dry weather can also cause forest fires, which are another source of environmental problems [1-4]. Drought in the northeast has long been a major problem, mainly due to rainfall. There are also other factors, including soil moisture, groundwater, and land use. Droughts are caused by low rainfall during the rainy season and its discontinuance in June in July. In addition, based on the analysis of the spatial and multi-temporal rainfall patterns, it was found that the discontinuance also occurred in the second half of September. The upper northeastern region is affected by drought seriously, as it is the area where 
the influence of the southwest monsoon cannot reach. And in any year, if there is no tropical cyclone passing through that line, it will cause more severe drought. The main impact of drought is the lack of water for water use in various activities, particularly agriculture and consumption. Agriculture is a major occupation in the northeast, so water shortages have had a severe impact on crop production. When agricultural crops are reduced, economic, social and environmental problems may arise, as well as health problems such as epidemics during drought [5].

Drought is more severe or less dependent on many factors, including physical, ecological, and human activity. Rainfall is therefore an important factor that should be used to find correlations with the spectral index [6-8]. In addition, in order to study the duration of rainfall that affects vegetation, the relationship between rainfall and the spectral index is an important parameter for determining drought areas [9-11]. Changes in the phenology of vegetation in arid areas can be seen as the difference in electromagnetic reflection by satellitebased data [12-14]. However, in drought studies, data may need to be optimized to make it more suitable for use or to improve the efficiency of the data for the study. This data optimization is called "index" [15-17]. The spectral index that correlates with physical condition of plants, water content in plants and soil can indicate drought condition. That is, growth and abundance of vegetation at different weather conditions (season) can be indicated by standardized vegetation index (SVI) calculations [18-20]. Based on the reasons and significance of the problem mentioned above, the purpose of this study is to present a drought analysis approach using satellite-based data and spectral index for the upper northeastern study area from 2014 to 2016 .

\section{Study Area and Data}

\section{Study Area}

The area used in this study is in upper northeastern Thailand (Fig. 1), located at latitude $16-18^{\circ}$ north and longitude $100-103^{\circ}$ east. Upper northeastern Thailand consists of 7 provinces: Loei, Nong Bua Lam Phu, Udon Thani, Nong Khai, Sakon Nakhon, Nakhon Phanom and Mukdahan, with a total area of about $52,504.65 \mathrm{~km}^{2}$.

\section{Operational Data}

\section{Data from Terra Modis Satellite}

The Terra Modis satellite is designed to track and monitor natural resources, with a swath of about 2,330 $\mathrm{km}$, spatial resolution of $250-1000 \mathrm{~m}, 36$ discrete spectral bands, and collecting data for every point of the earth's surface every 2 days. The data from the Terra Modis satellite is ideal for tracking large spatial variations like the northeastern part. In this study, two sets of MOD13Q1 products were used, h27v07 and h28v07, of which normalized differences vegetation index (NDVI) data sets covered the period from 2014 to 2016. Data from the satellite would go through the radiometric collection and mosaic image processing to combine the two sets of data and the upper northeastern study area. Then the value of the data was set under the mask to make the cloud area and the water area null and not used in the calculation.

\section{Rainfall Data}

This study uses the average monthly rainfall data for the years 2014, 2015 and 2016 to determine the

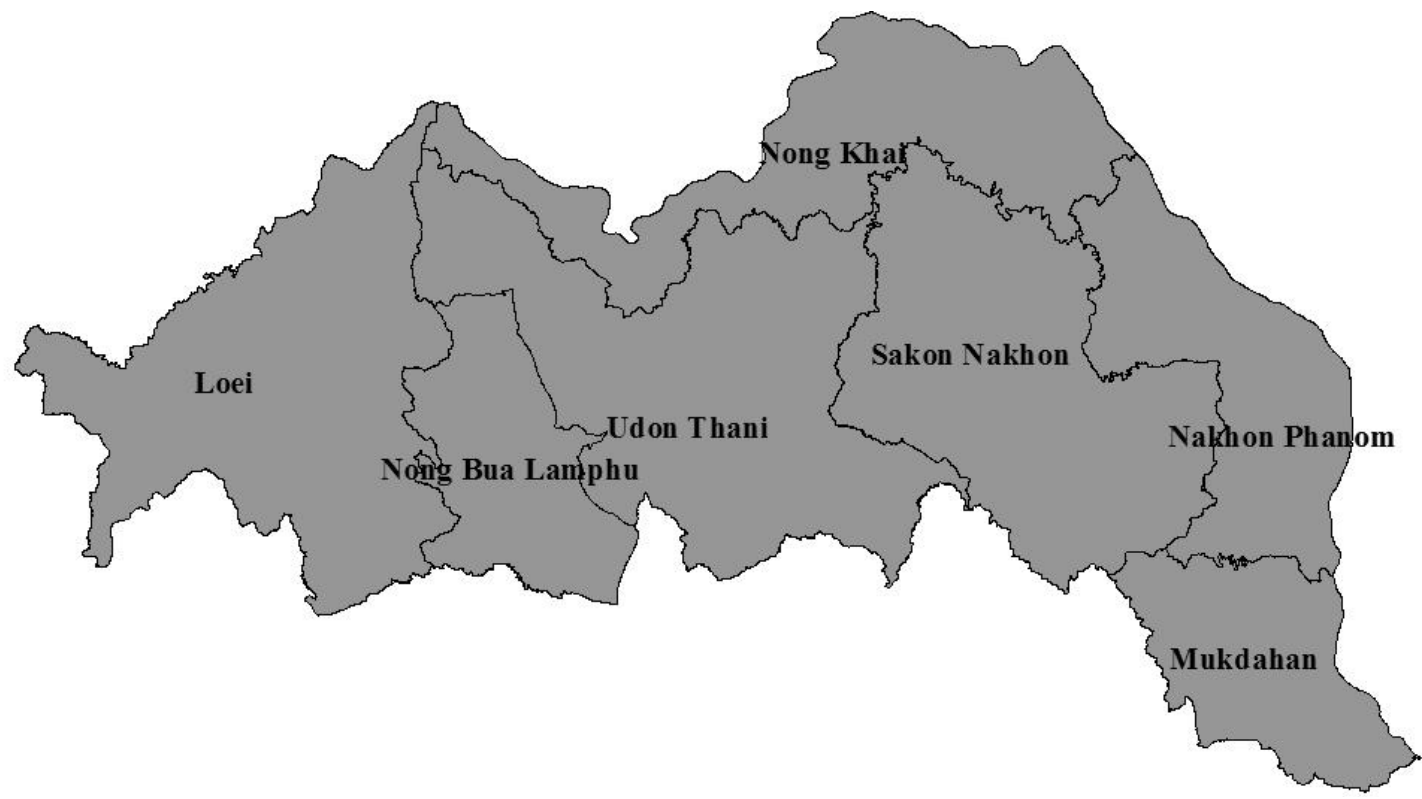

Fig. 1. Upper northeastern Thailand. 


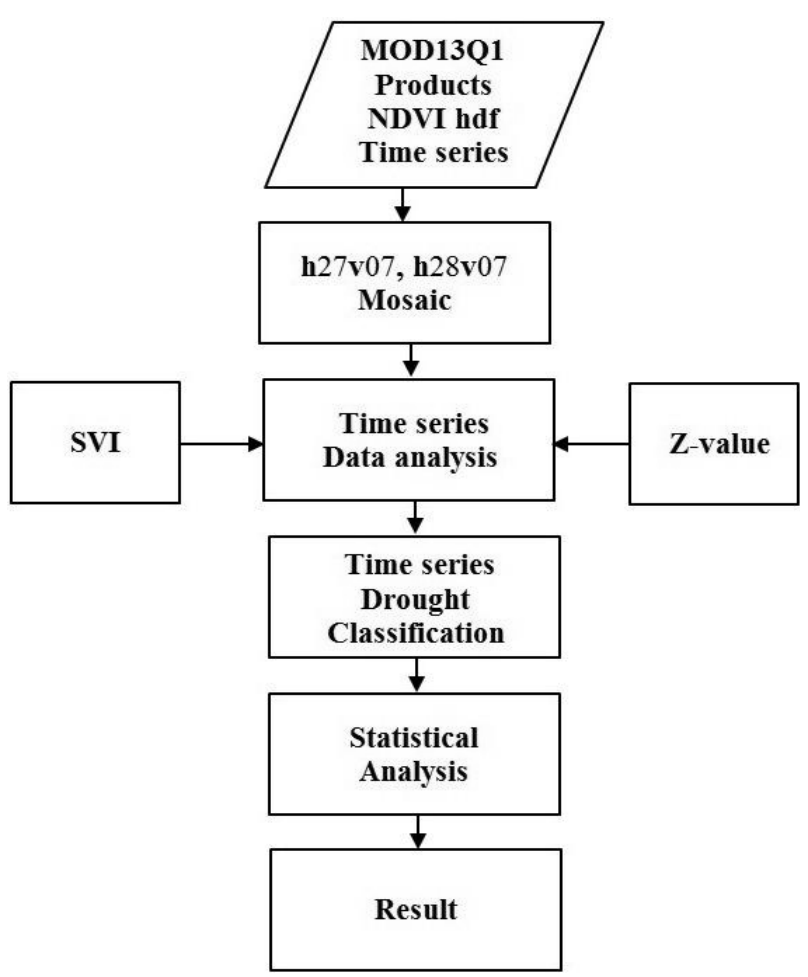

Fig. 2. Flowchart of the study.

temporal relationship with the SVI mean. Only rainfall monitoring ground stations of the Thai Meteorological Department located in the northeastern region were chosen for data collection.

\section{Operational Method}

In this study, the data analysis procedure was performed (Fig. 2). There were sequences of drought analysis using satellite data and spectral index in the upper northeastern region as follows.

\section{Data Collection from Terra Modis}

In this study, Terra Modis satellite-based data was collected from the USGS at https://earth explorer.usgs. gov/; monthly data for 2014-2016 were downloaded.

\section{SVI Analysis}

As SVI was a value derived from NDVI, the study used monthly data from Terra Modis from MOD13Q1 series with NDVI format, which was a useful and widespread indicator for monitoring vegetation dynamics. SVI was based on the z-score of each satellitebased pixel. The standard score was the deviation from average value in units of standard deviation calculated from NDVI of each pixel in each season (3 seasons in this study) according to the seasons in Thailand: the hot season (17 February to 16 May), the rainy season
(17 May to 16 October), and the cold season (17 October to 16 February). The standard score (z-score) was analyzed by equation 1 as follows [18]:

$$
Z_{i j k}=\frac{N D V I_{i j k}-\overline{N D V I_{i j}}}{\sigma_{i j}}
$$

...where:

$Z_{i j k}=$ the $\mathrm{z}$-value for pixel i during week $\mathrm{j}$ for year $\mathrm{k}$

$N D V I_{i j k}=$ the weekly NDVI value for pixel i during week $\mathrm{j}$ for year $\mathrm{k}$

$\overline{N D V I_{i j}}=$ the mean NDVI for pixel $\mathrm{i}$ during week $\mathrm{j}$ over $\mathrm{n}$ years and

$\sigma_{i j k}=$ the standard deviation of pixel i during week $\mathrm{j}$ over $n$ years

From equation 1 , the $Z_{i j k}$ value is a hypothesis value to be consistent with a standard normal distribution with the mean of 0 and standard deviation of 1 to examine hypothesis from pixel locations in each season of the years 2014, 2015 and 2016. The probability value of $\mathrm{SVI}=\mathrm{P}\left(Z_{i j k}\right)$ of the standard score of NDVI to reflect the probability of plant conditions. The SVI analysis can be seen in equation 2 [18]:

$$
S V I=\frac{\left(Z_{i j k}-Z_{i j M I N}\right)}{Z_{i j M A X}-Z_{i j M I N}}
$$

... where:

$Z_{i j k}=\mathrm{z}$-value for pixel $\mathrm{i}$ during week $\mathrm{j}$ for year $\mathrm{k}$

$Z_{i j M A X}^{i j k}=$ maximum of $\mathrm{z}$-value for pixel $\mathrm{i}$ during week $\mathrm{j}$ and

$Z_{i j M I N}=$ minimum of $\mathrm{z}$-value for pixel $\mathrm{i}$ during week $\mathrm{j}$

From Equation 2, the probability of each pixel was expressed as SVI, helping to visualize the greenness of the vegetation in terms of the probability of each pixel during different seasons of different periods. This study was conducted over a period of 3 years (2014-2016) to illustrate the comparison of high-level drought and lowlevel drought during such a period by seasons. It also estimated the probability of current vegetation from past vegetation. SVI was in the range of more than zero but less than one $(0<\mathrm{SVI}<1)$, where 0 was the lowest standard deviation of the NDVI at the pixel in that period over a period of 3 years, and 1 was the highest standard deviation of the NDVI at the pixel in that period over a period of 3 years.

\section{Spatial Analysis}

Spatial analysis of drought intensity was classified by critical levels of vegetation in each month of the years 2014, 2015 and 2016. SVI drought levels were classified into 5 levels (Table 1): 0.00-0.05 representing the lowest vegetation condition (very high drought) to 0.95 to 1.00 representing high vegetation (very low drought). 
Table 1. SVI level, percentage of SVI and drought level.

\begin{tabular}{|c|c|c|}
\hline SVI level & Percentage of SVI & Drought level \\
\hline $0.95-1.00$ (very high vegetation) & $96.0 \%-100 \%$ & Very low drought \\
\hline $0.75-0.95$ (high vegetation) & $76.0 \%-95.0 \%$ & Moderate drought \\
\hline $0.25-0.75$ (moderate vegetation) & $26.0 \%-75.0 \%$ & High drought \\
\hline $0.05-0.25$ (low vegetation) & $6.0 \%-25.0 \%$ & Very high drought \\
\hline $0.00-0.05$ (very low vegetation) & $0.0 \%-5.0 \%$ & \\
\hline
\end{tabular}

Multi-temporal analysis made it possible to more clearly see the overview over the three-year period (2014-2016). The SVI analysis result was analyzed together with the average monthly rainfall data for the years 2014, 2015 and 2016, from 22 rainfall monitoring ground stations of the Thai Meteorological Department covering only the upper northeastern region.

\section{Statistical Correlation Analysis}

The SVI analysis result from spatial analysis and rainfall data for the years 2014, 2015 and 2016 were used to find statistical correlations in the form of linear regression analysis.

\section{Results and Discussion}

\section{SVI Analysis Result}

The analysis result of SVI in monthly basis for 3 seasons, rainy hot and cool, presented the 3-year average of SVI (2014-2016) as shown in Fig. 3. The graph clearly showed SVI variability. In addition, the analysis result of SVI in monthly basis for the years 2014, 2015 and 2016 showed the different vegetation conditions in the range of 0 to 1 , based on the theory mentioned above. The average indicated the vegetation or drought condition in each period and each season. The result showed that 2014 had the highest average of 0.38 (standard deviation

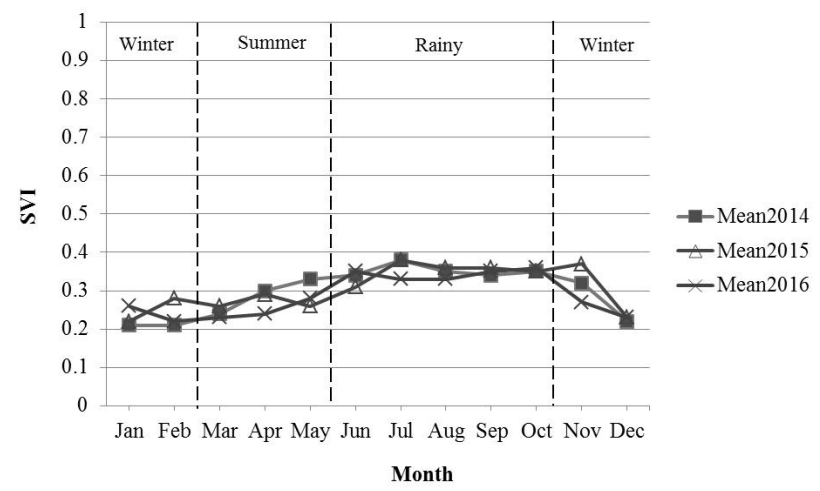

Fig. 3. SVI analysis result.
0.27 ) in July in the rainy season, and the lowest in 0.21 (standard deviation 0.31) in January and February in the late cold season. 2015 had the highest average of 0.38 (standard deviation 0.27) in July in the rainy season, and the lowest in 0.22 in January (standard deviation 0.30) and February in the late cold season. And 2016 had the highest average of 0.36 (standard deviation 0.26 ) in October in the rainy season, and the lowest in 0.22 (standard deviation 0.30 ) in February in the late cold season.

\section{Spatial Drought Intensity Analysis Results}

Drought analysis using satellite-based data and vegetation change showed that the SVI variability at different times depended on rainfall, which determined the drought. A comparison of SVI data for several seasons in each year showed different vegetation changes. SVI spatial data clearly reflected the different levels of vegetation in each area. Areas with vegetation abnormalities in 2014, 2015 and 2016 are shown in Figs 4-6.

Fig. 4 shows the upper northeastern region in 2014; in the hot season (17 February to 16 May) the lowest vegetation was in March. The distribution of vegetation was very high in May. In the rainy season (17 May to 16 October) the lowest vegetation was in June, then the highest vegetation was in September. And in the cold season (17 October to 16 February) the distribution of vegetation was very high in November, then the vegetation began declining until December in 2014. In Fig. 5 the upper northeastern region in 2015 in the hot season (17 February to 16 May) the lowest vegetation was in April. The distribution of vegetation was very high in May. In the rainy season (17 May to 16 October) the lowest vegetation was in July, then the highest vegetation was in September. And in the cold season (17 October to 16 February) the distribution of vegetation was very high in November, then the vegetation began declining until December in 2015. From Fig. 6, the upper northeastern region in 2016, in the hot season (17 February to 16 May) the lowest vegetation was in March. The distribution of vegetation was very high in May. In the rainy season (17 May to 16 October) the lowest vegetation was in June, then the highest vegetation was in October. And in the cold season (17 October to 16 February) the distribution of vegetation 


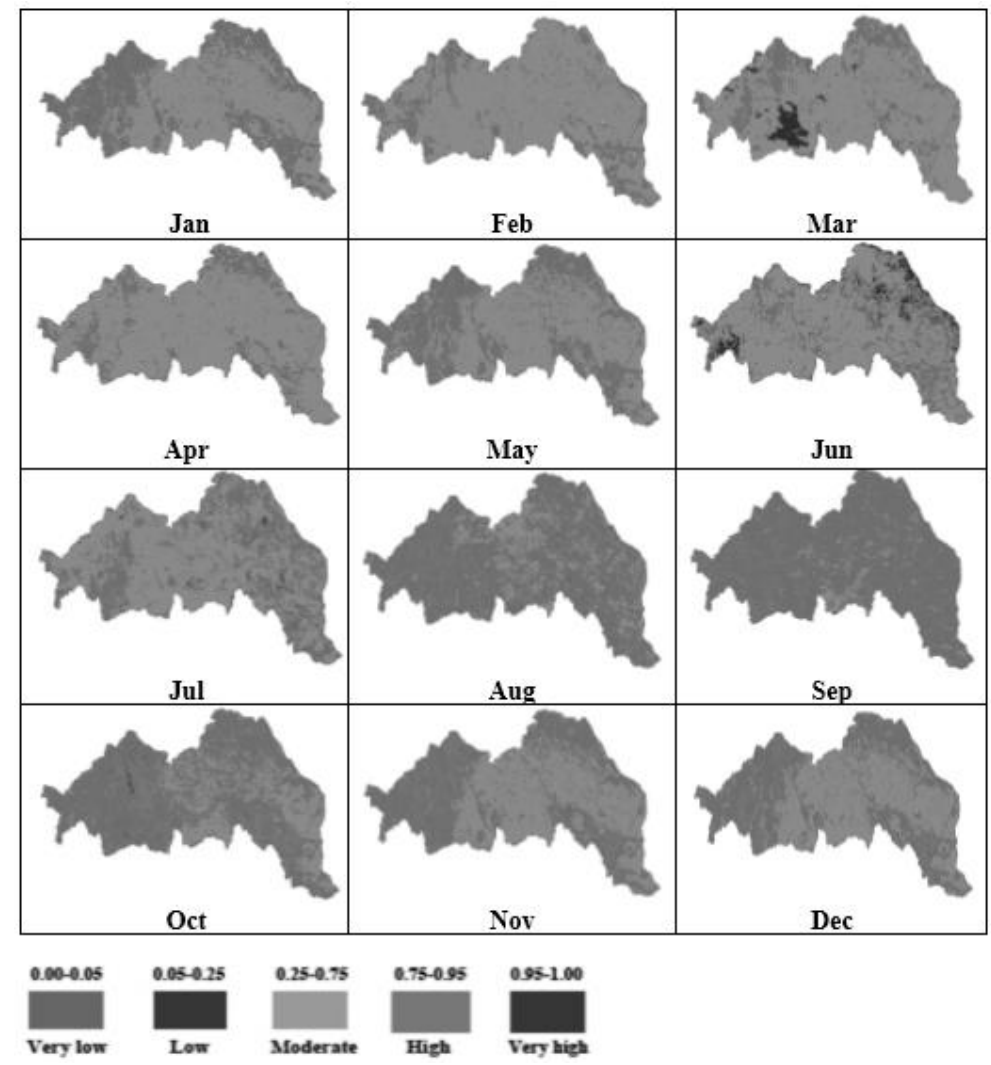

Fig. 4. Spatial drought intensity analysis result for 2014 .

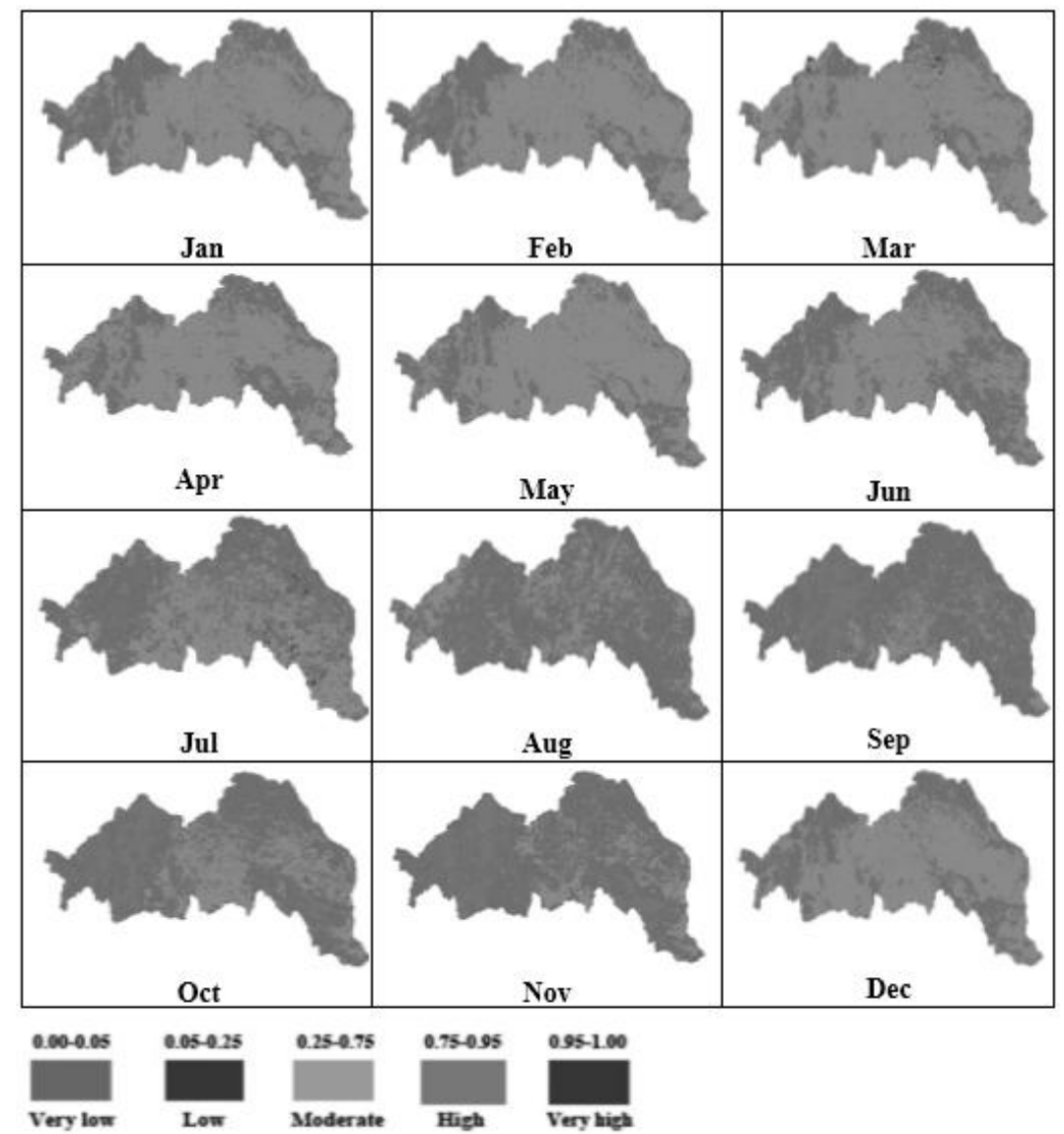

Fig. 5. Spatial drought intensity analysis result for 2015. 


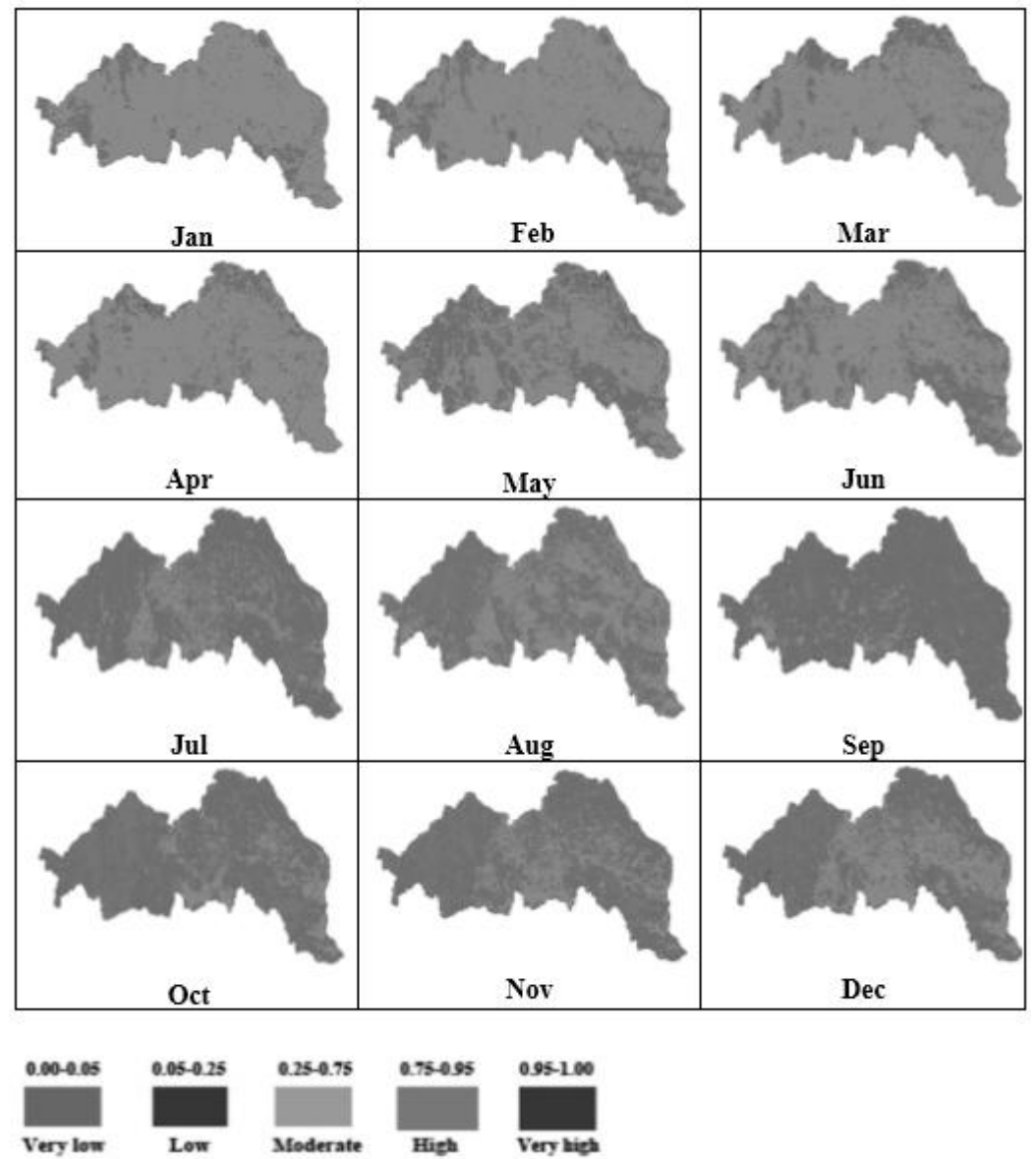

Fig. 6. Spatial drought intensity analysis result for 2016 .

was very high in November, then the vegetation began declining until December in 2016.

In addition to the analysis mentioned above, this study also analyzed the annual SVI by overlaying data from monthly data, which made it possible to reflect spatial and temporal droughts more precisely than monthly. As shown in Fig. 7, the most severe spatial drought was in 2014, followed by the years 2015 and 2016, respectively
Multi-Temporal Drought Analysis Result

SVI monthly average and rainfall over 3 years (Fig. 8) showed that the temporal variation of the SVI average corresponded to the monthly rainfall, but the change in SVI was slower than that of rainfall because vegetation developed after sufficient water for growth or leaf production. Multi-temporal drought analysis was summarized as follows. In 2014, rainfall variations were

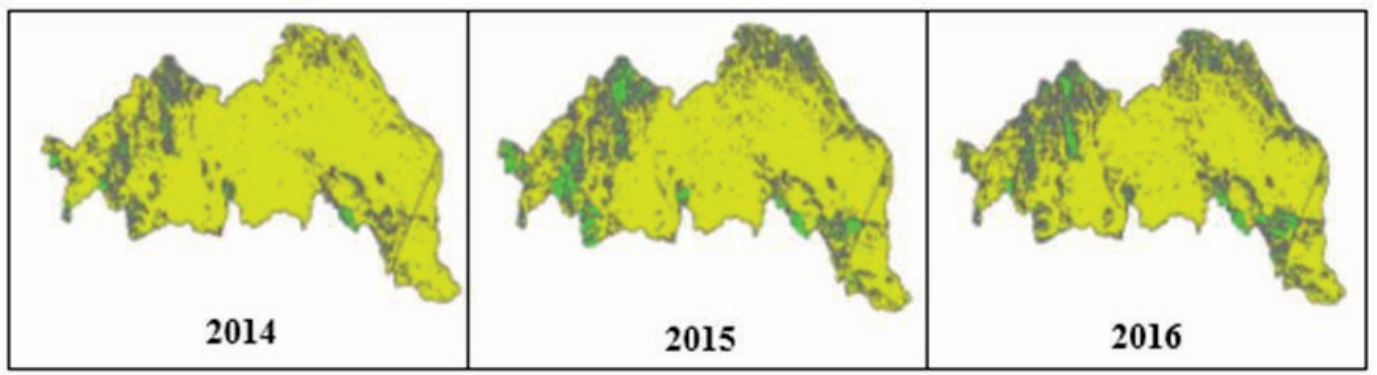

$0.00-0.05 \quad 0.05-0.25 \quad 0.25-0.75 \quad 0.75-0.95 \quad 0.95-1.00$

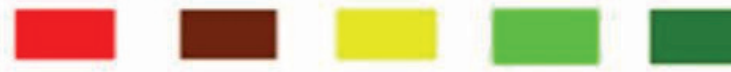

Fig. 7. SVI yearly analysis. 


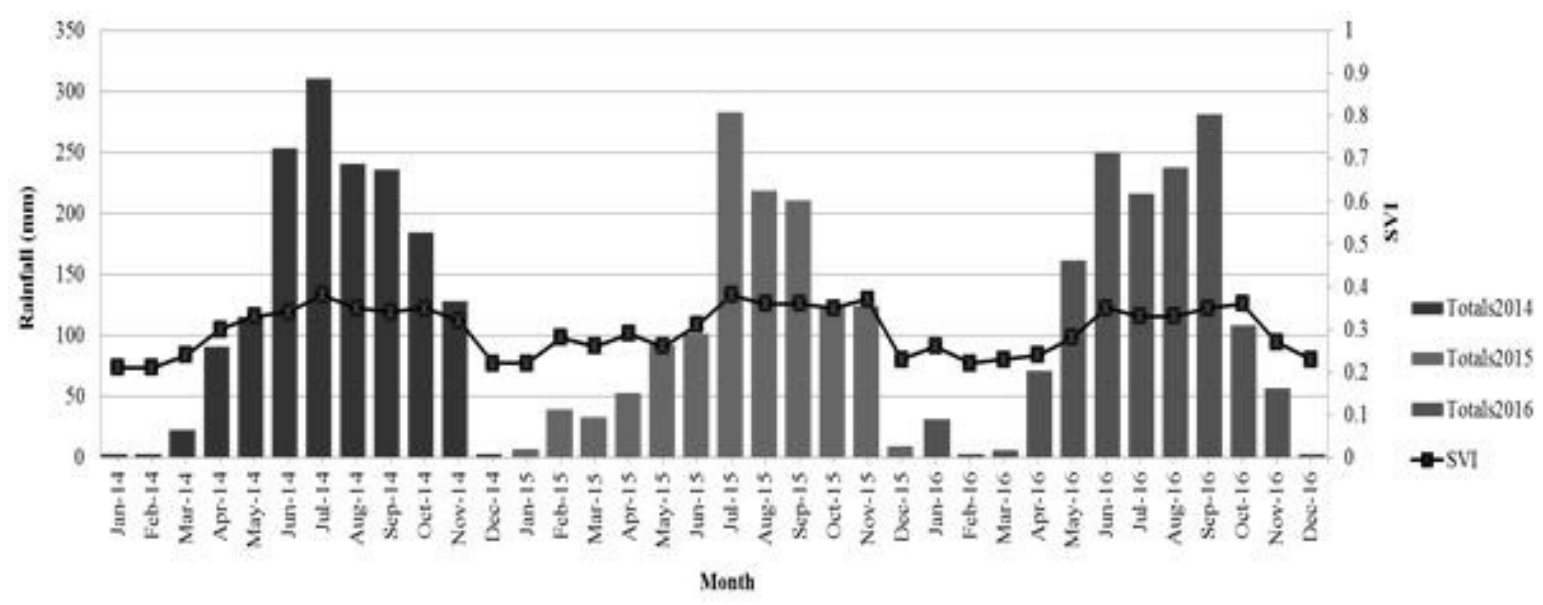

Fig. 8. Multi-temporal drought analysis result.

lowest in January and February, then increased steadily and reached a peak in July, and dropped to the lowest in December. In 2015, rainfall variations were lowest in January, then increased steadily and reached a peak in July, and dropped to the lowest in December. In 2016, rainfall variations were slightly higher in January, then dropped until March, and increased steadily and reached a peak in September, then dropped steadily and reach their lowest in December.

\section{Statistical Correlation Analysis Result}

Statistical correlation analysis result between SVI (independent variable) and rainfall (dependent variable) in 2014, 2015 and 2016 showed that the SVI variation was consistent with or correlated with the amount of rainfall. Statistical correlation analysis results between SVI and rainfall in 2014 provided a correlation equation $\mathrm{y}=1686.8 \mathrm{x}-372.56$ and a coefficient of determination $\mathrm{R}^{2}=0.88$. The statistical correlation analysis result between SVI and rainfall in 2015 provided a correlation equation $\mathrm{y}=1379.4 \mathrm{x}-314.35$ and a coefficient of determination $\mathrm{R}^{2}=0.78$. And statistical correlation analysis result between SVI and rainfall in 2016 provided a correlation equation $\mathrm{y}=1703.8 \mathrm{x}-371.43$ and a coefficient of determination $\mathrm{R}^{2}=0.74$.

\section{Conclusions}

In this study, the average SVI could be used as a comparison operator. Low SVI values implied drought; and the closer to 0 , the more severe the drought. In contrast, high SVI implied abundance; the closer to 1 , the more abundance and no drought. The study also found that the largest drought area was in 2014, representing $93.12 \%$ (or $48,892.33 \mathrm{~km}^{2}$ ), followed by the year 2015 representing $87.02 \%$ (or $45,689.54 \mathrm{~km}^{2}$ ), and the year 2016 representing $86.42 \%$ (or $45,374.51 \mathrm{~km}^{2}$ ). Multi-temporal drought analysis results between SVI and rainfall showed that the average monthly average of SVI and rainfall were consistent with each other over the 3-year study period, as shown in the standard graph in Figure 8. That is, if rainfall increased, SVI increased accordingly. On the other hand, if rainfall decreased, SVI decreased accordingly. However, the change in SVI was slower than that of rainfall because vegetation developed after sufficient water for growth or leaf production. In addition, statistical correlation analysis between SVI (independent variable) and rainfall (dependent variable) on a monthly basis of all 3 years (2014-2016) showed that in 2014 the coefficient of determination $\mathrm{R}^{2}=0.88$, in $2015 \mathrm{R}^{2}=0.78$, and in $2016 \mathrm{R}^{2}=0.74$. The coefficient of determination of all three years approached 1, indicating a high correlation.

We also found that the result was in the same direction with other research such as an evaluation of drought risk area in northeastern Thailand using remotely sensed data and GIS [21], exploration of spatio-temporal drought patterns using satellite-derived indices for crop management in northeastern Thailand [22], and using standardized vegetation index to assess drought areas in northeastern Thailand [23]. Therefore, the results of this study provide a rational basis for determining the drought-prone areas of the upper northeastern region. It also quickly and reliably provides drought area assessment. Relevant agencies can use this method to analyze drought areas and apply the results to develop sustainable drought prevention and mitigation plans in other areas of Thailand.

\section{Acknowledgements}

This research was financially supported by Mahasarakham University (Fast Track 2019).

\section{Conflict of Interest}

The authors declare no conflict of interest. 


\section{References}

1. ZHANG Y. On the Climatic Uncertainty to the Environment Extremes: a Singapore Case and Statistical Approach. Polish Journal of Environmental Studies, 24 (3), 1413, 2015.

2. LAOSUWAN T., SANGPRADID S., GOMASATHIT T., ROTJANAKUSOL T. Application of Remote Sensing Technology for Drought Monitoring in Mahasarakham Province, Thailand. International Journal of Geoinformatics, 12 (3), 17, 2016.

3. WANG J., WANG, S., LI Y., HE W., LIU X., REN Y. A Study of the K Drought Monitoring Model. Polish Journal of Environmental Studies, 27 (1), 335, 2018.

4. SENIN R. M., ION I., ION A.C., A Sorption Study of Bisphenol A in Aqueous Solutions on Pristine and Oxidized Multi-Walled Carbon Nanotubes. Polish Journal of Environmental Studies, 27 (5), 2245, 2018.

5. UTTARUK Y., LAOSUWAN T. Drought Detection by Application of Remote Sensing Technology and Vegetation Phenology. Journal of Ecological Engineering, 18 (6), 115, 2017.

6. NIGHTINGALE J.M., PHINN S.R. Assessment of relationships between precipitation and satellite derived vegetation condition within South Australia. Australian Geographical Studies, 41, 180, 2003.

7. GESSNER U., NAEIMI V., KLEIN I., KUENZER C., KLEIN D., DECH S. The relationship between precipitation anomalies and satellite-derived vegetation activity in Central Asia. Global and Planetary Change, 110, 74, 2013.

8. GOMASATHIT T., LAOSUWAN T., SANGPRADID S., ROTJANAKUSOL T. Assessment of Drought Risk Area in Thung Kula Rong Hai using Geographic Information System and Analytical Hierarchy Process. International Journal of Geoinformatics, 11 (2), 21, 2015.

9. KOGAN F., GUO W. Agricultural Drought Detection and Monitoring Using Vegetation Health Methods. In Remote Sensing of Water Resources, Disasters, and Urban Studies; THENKABAIL P.S., Ed.; CRC Press: Boca Raton, FL, USA, 339, 2015.

10. FONTES D.S., SOUSA L., BRAGA C.C., BRAGA R.C., DANTAS M.P. Interrelationship between Rainfall and Vegetation Index by Remote Sensing. Journal of Human Reproductive Sciences, 4, 87, 2014.

11. RIMKUS E., STONEVICIUS E., KIPYS J., MACIULYTE V., VALIUKAS D. Drought Identification in the Eastern Baltic Region using NDVI. Earth System Dynamics, 8, 627, 2017.

12. TUCKER C.J. Red and Photographic Infrared Linear Combinations for Monitoring Vegetation. Remote Sensing of Environment, 8 (2), 127, 1979.

13. WU J., ZHOU L., LIU M., ZHANG J., LENG S., DIAO C. Establishing and Assessing the Integrated Surface Drought
Index (ISDI) for Agricultural Drought Monitoring in Mideastern China. International Journal of Applied Earth Observation and Geoinformation, 23, 397, 2013.

14. VRIELING A., MERONI M., SHEE A., MUDE A.G., WOODRAD J., DE BIE C.K., REMBOLD F. Historical Extension of Operational NDVI Products for Livestock Insurance in Kenya. International Journal of Applied Earth Observation and Geoinformation, 28, 238, 2014.

15. WANG J., RICH P.M., PRICE K.P. Temporal Responses of NDVI to Precipitation and Temperature in the Central Great Plains, USA. International Journal of Remote Sensing, 24 (11), $2345,2013$.

16. DUTTA D., KUNDU A., PATEL N.R., SAHA S.K., SIDDIQUI A.R. Assessment of Agricultural Drought in Rajasthan (India) using Remote Sensing Derived Vegetation Condition Index (VCI) and Standardized Precipitation Index (SPI). The Egyptian Journal of Remote Sensing and Space Sciences, 18, 53, 2015.

17. JIAO W., ZHANG L., CHANG Q., FU D., CEN Y, TONG Q. Evaluating an Enhanced Vegetation Condition Index (VCI) Based on VIUPD for Drought Monitoring in the Continental United States. Remote Sensing, 8, 2, 2016.

18. PETERS J.A., WALTER-SHEA E.A., JI L., ANDRES V., MICHAEL H., SVOBODA M.D. Drought Monitoring with NDVI-Based Standardized Vegetation Index. Photogrammetric Engineering \& Remote Sensing, 68 (1), 71, 2002.

19. PARK J.S., KIM K.T., CHOI Y.S. Application of Vegetation Condition Index and Standardized Vegetation Index for Assessment of Spring Drought in South Korea, in IGARSS 2008-2008 IEEE International Geoscience and Remote Sensing Symposium, 3, 774, 2008.

20. WATTANAKIJ N., MONGKOLSAWAT C. Drought Detection in Northeast Thailand using Standardized Vegetation Index of Multi-Temporal Satellite Data, In: Proc. 4th Environment Naresuan Conference, Naresuan University, Thailand, 206, 2008.

21. MONGKOLSAWAT C., THIRANGOON P., SUWANWERAKNAMTORN R., KARLADEE N., PAIBOONSAK S., CHAMPATHET P. An Evaluation of Drought Risk Area in Northeast Thailand using Remotely Sensed Data and GIS. Asian Journal of Geoinformatics, 1 (4), 33, 2001.

22. MONGKOLSAWAT C., WATTANAKIJ N., KAMCHAI T. Exploration of Spatio-Temporal Drought Patterns using Satellite-Derived Indices for Crop Management in Northeastern Thailand. Proceedings of the 30th Asian Conference on Remote Sensing China.18-23 October 2009. Beijing, China, 2009.

23. SEEKAW A., MONGKOLSAWAT C., SUWANWERAKNAMTORN R. Using standardized vegetation index to assess drought areas in Northeast Thailand. Journal of Remote Sensing and GIS Association of Thailand. 15 (2), 25, 2014. 